\title{
Martian sub-surface ionising radiation: biosignatures and geology*
}

\author{
L. R. Dartnell ${ }^{1}$, L. Desorgher ${ }^{2}$, J. M. Ward ${ }^{3}$, and A. J. Coates ${ }^{4}$ \\ ${ }^{1}$ CoMPLEX (Centre for Mathematics \& Physics in the Life Sciences and Experimental Biology), University College London, \\ UK \\ ${ }^{2}$ Physikalisches Institut, University of Bern, Switzerland \\ ${ }^{3}$ Department of Biochemistry and Molecular Biology, University College London, UK \\ ${ }^{4}$ Mullard Space Science Laboratory, University College London, UK \\ *Invited contribution by L. R. Dartnell, one of the Union Young Scientist Award winners 2006.
}

Received: 8 January 2007 - Published in Biogeosciences Discuss.: 9 February 2007

Revised: 31 May 2007 - Accepted: 15 June 2007 - Published: 30 July 2007

\begin{abstract}
The surface of Mars, unshielded by thick atmosphere or global magnetic field, is exposed to high levels of cosmic radiation. This ionising radiation field is deleterious to the survival of dormant cells or spores and the persistence of molecular biomarkers in the subsurface, and so its characterisation is of prime astrobiological interest. Here, we present modelling results of the absorbed radiation dose as a function of depth through the Martian subsurface, suitable for calculation of biomarker persistence. A second major implementation of this dose accumulation rate data is in application of the optically stimulated luminescence technique for dating Martian sediments.

We present calculations of the dose-depth profile in the Martian subsurface for various scenarios: variations of surface composition (dry regolith, ice, layered permafrost), solar minimum and maximum conditions, locations of different elevation (Olympus Mons, Hellas basin, datum altitude), and increasing atmospheric thickness over geological history. We also model the changing composition of the subsurface radiation field with depth compared between Martian locations with different shielding material, determine the relative dose contributions from primaries of different energies, and discuss particle deflection by the crustal magnetic fields.
\end{abstract}

\section{Introduction and background}

\subsection{Astrobiology and Mars}

There is the possibility that early Mars was conducive to the development of life. Large-scale geomorphological ev-

Correspondence to: L. R. Dartnell

(1.dartnell@ucl.ac.uk) idence suggests the action of liquid water: extensive valley networks, great floods channels, pooling in crater lakes, and estuarine deposition fans (Jaumann et al., 2001; Masson et al., 2001). More recently, NASA's Mars Exploration Rover Opportunity found unmistakable signs of the chemical action of liquid water, final proof of a sea once having covered Meridiani Planum (Squyres et al., 2004). The persistence of such liquid water on the surface requires a higher atmospheric pressure and more effective greenhouse effect than at present. Similar to the primordial terrestrial situation, a significant amount of organic molecules, precursors to the biochemistry that developed on Earth, is expected to have been delivered by comet and meteorite fall onto this warmer wetter Mars (Flynn, 1996).

Today, however, the Martian surface is a harshly inhospitable place. Atmospheric loss has left a surface pressure of around only $6 \mathrm{mbar}$ and a daily mean equatorial temperature of $215 \mathrm{~K}$ (Carr, 1996). This regime lies beneath the triplepoint of water, and so it is not stable in a liquid state on the surface. Consequently water, a solvent thought critical for the origin and persistence of life, exists only as inaccessible ice or subliming directly into atmospheric vapour. The Martian surface is a cold barren desert.

A further hazard to surface life is that the thin atmosphere offers practically no protection against solar ultraviolet. This energetic radiation readily photolyses biomolecules such as amino acids and DNA and inhibits chlorophyll (ten Kate et al., 2005; Cockell, 2000a), and a bacterial cell lying exposed on the Martian surface would be inactivated within minutes (Schuerger et al., 2006). Furthermore, the high UV flux is believed to have created an oxidising layer in the Martian topsoil, hypothesised to explain the failure of Viking to detect any organic material down to parts per

Published by Copernicus Publications on behalf of the European Geosciences Union. 
billion levels (Yen et al., 2000), not even that expected from meteoritic infall (Flynn, 1996). Although the possibility of cryptoendoliths, communities contained within the more clement micro-environment and UV protection of rock fissures, analogous to those found in the Antarctic dry valleys has been discussed (Cockell, 2000b), the combination of very low water availability, high UV flux, oxidation hazard and scarcity of organic molecules renders the Martian top surface extremely inhospitable (Clark, 1998).

A great amount of water is believed to remain on Mars, probably soaked down into the sponge-like regolith, thought to be highly porous and brecciated to an appreciable depth from the heavy bombardment (Squyres, 1984). There exists the possibility, therefore, that chemosynthetic Martian life remains alive to this day far underground, where the internal heat of the planet melts the underside of the permafrost shell into a liquid water aquifer (Boston et al., 1992), and has been proposed as the source of the recently-detected atmospheric methane (Formisano et al., 2004; Krasnopolsky, 2006). Such a habitat would be analogous to the deep hot biosphere known on Earth, with bacteria discovered within a bore hole at $5.3 \mathrm{~km}$ depth (Szewzyk et al., 1994). On Mars, the depth necessary for the ambient temperature to rise high enough for liquid water is calculated to be around $3.7 \mathrm{~km}$ at the equator, increasing to $6-7 \mathrm{~km}$ in mid-lattitudes, but these estimates are dependent on estimated parameters such as the geothermal gradient and freezing point depression from salt concentration (Hoffman, 2001). Life may also survive in small refugial habitats nearer the surface around local geothermal hotspots, such as the Tharsis or Elysium volcanic regions. However, gaining access to such a deep environment on Mars is technologically unfeasible for the foreseeable future: a $5-10 \mathrm{~km}$ bore-hole on Mars would require substantial drilling equipment, and almost certainly human supervision (Close et al., 2005). The maximum depth obtainable by near-future robotic probes will be on the order of only meters. ESA's ExoMars rover, currently planned for launch in 2013, has been designed with a $2 \mathrm{~m}$ drill bit (Vago et al., 2006). In this accessible region any microbes will likely be dormant, cryopreserved by the current freezing conditions, and so metabolically inactive and unable to repair cellular degradation as it occurs. The primary environmental hazard to cells and remnant biological molecules beneath the UV-induced oxidising layer (and so safe from rapid chemical degradation) is the accumulation of radiation damage from exogenous ionising particles. The depth of the oxidising layer is difficult to constrain but is probably not substantially greater than one meter (Zent, 1998); overlapping the region where such ionising radiation will be a crucial limiting factor on persistence times. The problem of oxidation can be minimised by searching at the bottom of a recent impact crater or boulders in the ejecta blanket, or the putative Cerberus pack-ice (Murray et al., 2005).

\subsection{Space radiation environment}

The space ionising radiation environment at Mars is composed of two populations of particles. Solar energetic protons (SEP) are accelerated by flares and coronal mass ejections, typically up to several hundred $\mathrm{MeV}$, and so the flux is dependent on the 11-year solar activity cycle. The peak flux of galactic cosmic ray (GCR) particles, at around $500 \mathrm{MeV} /$ nucleon, is about four orders of magnitude lower than SEP but the power law tail of the spectra extends up to $10^{20} \mathrm{eV}$ at extremely low fluxes. The GCR spectrum is composed of $85 \%$ protons, $14 \%$ alpha (helium nuclei), and a small fraction of heavy ions (fully ionised atomic nuclei) and electrons, and is thought to be mainly accelerated by Type II supernovae. GCR below about $1 \mathrm{GeV} /$ nucleon are modulated by the heliosphere (Klapdor-Kleingrothaus and Zuber, 2000) so their flux is anticorrelated with the solar activity cycle.

Figure 1 plots the GCR energy spectra for proton and helium ion primaries, for both solar maximum and solar minimum conditions, given by the CREME96 model. The mean SEP flux (Usoskin et al., 2006) is also shown transformed using the inverse square law to provide a spectrum appropriate for Martian orbit. Solar particle events produce a harder spectrum than this mean shown, with an enhancement in flux at energies up to several $\mathrm{GeV}$, but these are short-lived and rare. Thus, SEP and GCR primaries represent two complimentary populations of ionising particles; high flux but relatively low energy and much lower flux but extending up to very high energy levels, respectively. Although SEP can produce transiently high dose rates on the Martian surface, averaged over the long timescales of interest here their subsurface dose contribution is dominated by GCR (Mileikowsky et al., 2000; Dartnell et al., 2007) and so are not considered further in this modelling study.

Unlike Earth, the Martian surface is unprotected from cosmic particle radiation by a global dipole magnetic field or sufficient atmospheric shielding. However, the distribution of anomalous strong localised crustal magnetic fields in the ancient highlands suggest Mars did once have an internal dynamo that failed early in the planet's history (Acuna et al., 1999).

Figure 2 shows our calculated maps of surface flux of one million $10 \mathrm{MeV}$ electrons and protons propagating through the most intense crustal magnetic fields over Terra Sirenum, modelled with the PLANETOCOSMICS package (http://cosray.unibe.ch/ laurent/planetocosmics/) using the CAIN90 spherical harmonic model of the crustal magnetic fields (Cain et al., 2003). Such low energy electrons can be seen to experience significant deflection by the anomalies, producing a protective umbrella effect of particle shadows where no flux strikes the surface surrounded by pileup regions of focused flux. The maximum horizontal field vector in the Terra Sirenum region below $200 \mathrm{~km}$ altitude is on the order of $1 \mu \mathrm{T}$. We calculate the gyroradius of a perpendicularly-incident $10 \mathrm{MeV}$ electron to be $35 \mathrm{~km}$, and 


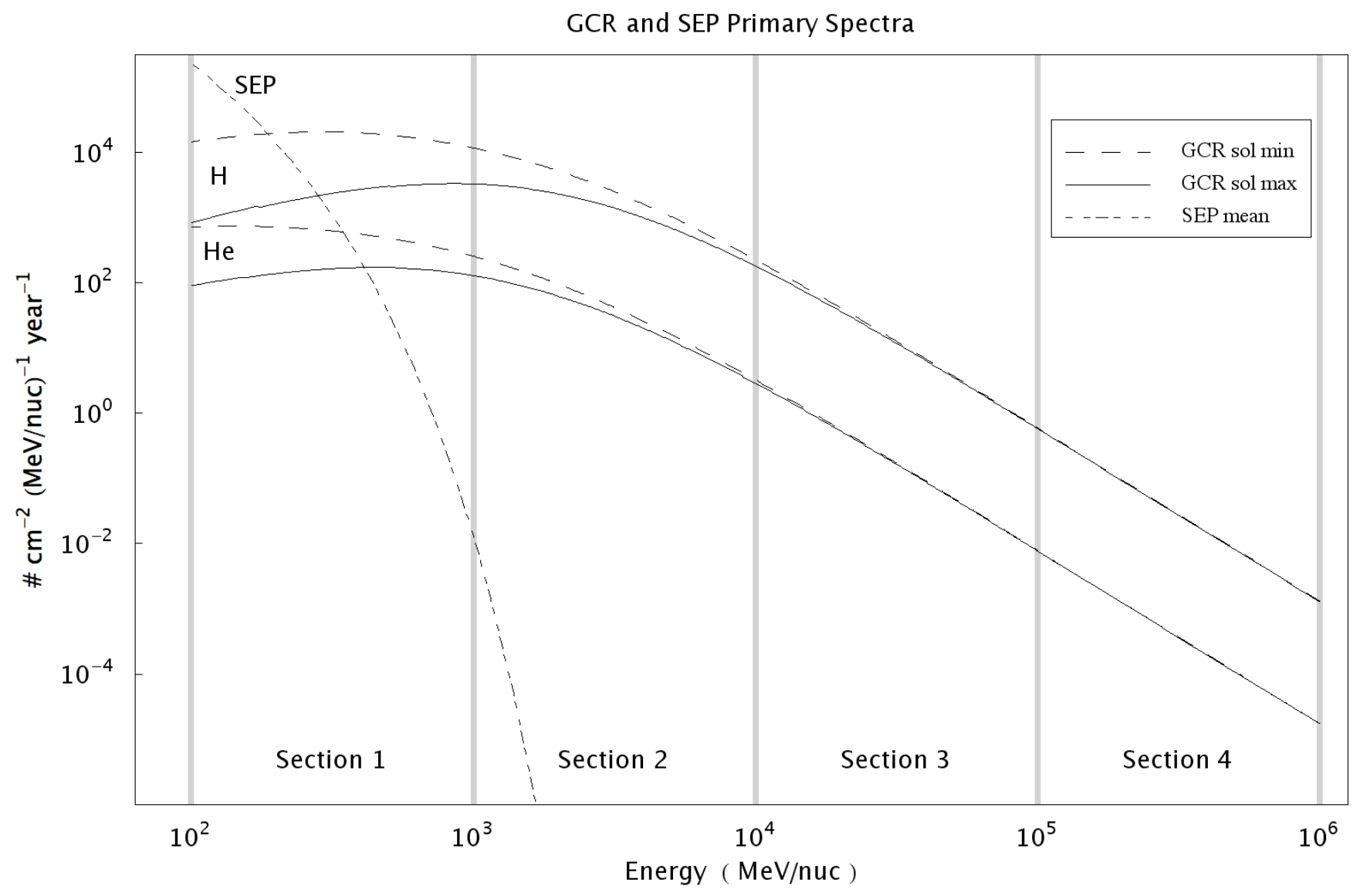

Fig. 1. Primary spectra for GCR H and He primaries under solar minimum and maximum conditions and annual mean SEP impinging on Mars. Also shown are the divisions into separate energy ranges used during this modelling.

so it is effectively deflected as it spirals along the field lines. Protons of equal energy have a much larger gyroradius of $460 \mathrm{~km}$ and are only minimally deflected. These simulations were performed without modelling particle attenuation by the atmosphere, however, and none of these primaries would in fact reach the surface. More penetrating primaries with an energy of around $1 \mathrm{GeV}$, corresponding to the peak GCR proton flux, have gyroradii in these field strengths of nearly $6000 \mathrm{~km}$, and so experience negligible deflection. These crustal fields can thus be ignored in modelling the subsurface radiation environment on Mars.

Energetic GCR primary ions produce extensive showers of secondary particles in the terrestrial atmospheric column. When a GCR strikes an atmospheric nucleus energetic secondary mesons (pions and kaons), nucleons, gammas and nuclear fragments are produced, which then interact with other nuclei. Secondary mesons decay over a short timescale to produce muons, gamma rays and electrons. Thus the air shower is composed of a central "hard component" core of nuclear fragments within a spreading "soft component" cone of the electromagnetic cascade (Eidelman et al., 2004). The flux of secondaries builds with increasing shielding depth until the Pfotzer maximum, after which the average particle energy is below the threshold for new particle production and the cascade steadily decays. On Earth, this Pfotzer maximum occurs at an altitude of around $15 \mathrm{~km}$; roughly the cruising altitude of Concorde. Similarly-structured cascades occur not in the thin Martian atmosphere, but in the top meters of the ground.

\subsection{Radiobiology}

The ionising radiation field produced by SEP and GCR is harmful to life (Nelson, 2003) through both direct and indirect mechanisms. Direct damage occurs when deposited energy excites electrons within biomolecules, leading to ionisation or radiolysis. However, radiation primarily interacts with water as it comprises $40-70 \%$ of cells and $20 \%$ of bacterial spores, and this creates highly-reactive species such as the hydroxyl radical or hydrogen peroxide that then diffuse and attack biomolecules (the indirect mechanism) (Baumstark-Khan and Facius, 2001). The amount of energy deposited by ionising radiation in the target material per unit 

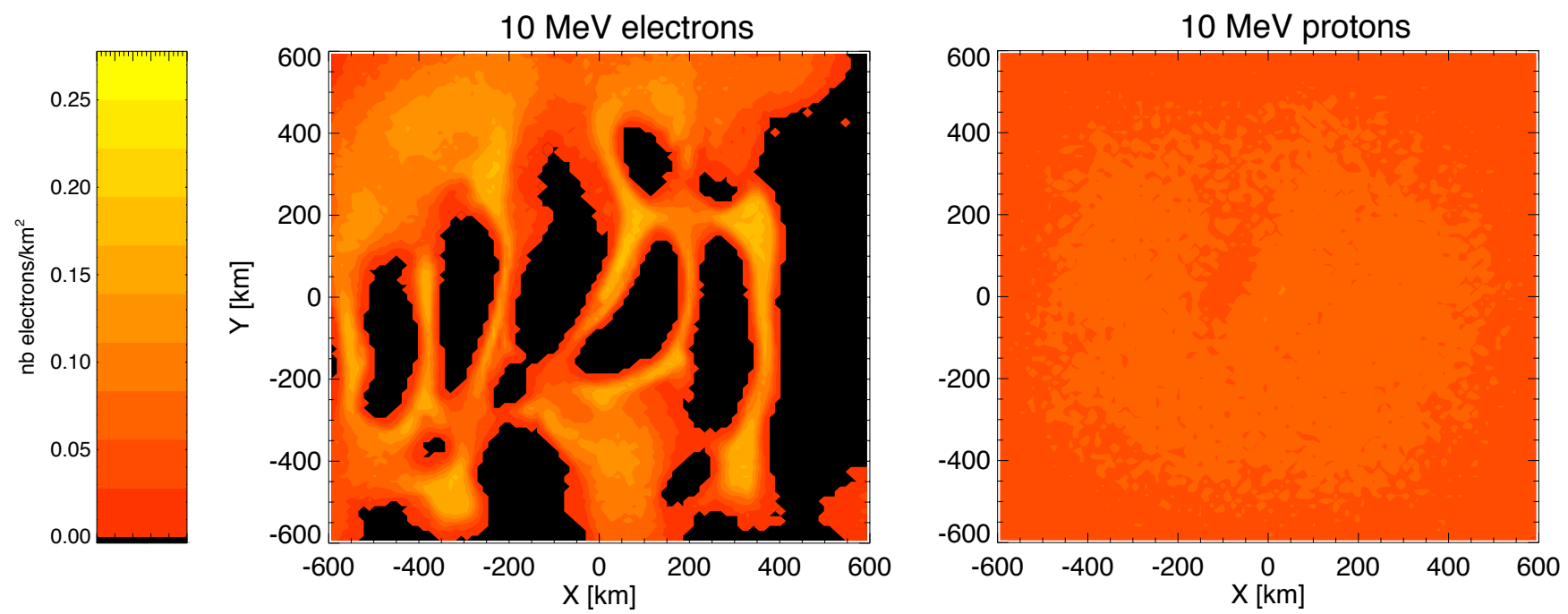

Fig. 2. Surface flux maps of modelled $10 \mathrm{MeV}$ electrons and protons propagating through the most intense magnetic anomalies over Terra Sirenum, centred on $-47.8 \mathrm{~N} 174 \mathrm{E}$.

mass is termed the dose, measured in $\mathrm{J} / \mathrm{kg}$, or Grays (Gy). Different particles of ionising radiation are not equally hazardous to cells. Gamma radiation is weakly ionising, and on scales larger than micrometers the energy of a given dose is deposited uniformly throughout the target. The protons and high-charge/high-energy (HZE) ions of the hadronic cascade, however, are highly ionising and deposit energy in a dense track. Such a pattern of dose deposition is measured as a high value of linear energy transfer (LET). HZE tracks can cause clusters of nearby breaks in DNA strands and are therefore particularly detrimental to cellular survival.

No ionising radiation detector has yet been landed on the Martian surface, although NASA's Mars Science Laboratory (scheduled launch 2009) will carry the Radiation Assessment Detector (Hassler et al., 2006) and the GEORAD package has been proposed for ESA's ExoMars (scheduled launch 2013) to detect solar proton and neutron backscatter flux (an indirect measure of GCR) (Ambrosi et al., 2005). Until these return observational data, computer modelling will be crucial in determining the Martian radiation environment both on the ground and beneath. Previous modelling research has calculated the expected survival times of different model organisms (terrestrial microbes exhibiting varying degrees of radioresistance) in the face of accumulating radiation dose (Mileikowsky et al., 2000; Pavlov et al., 2002; Dartnell et al., 2007). We have previously reported (Dartnell et al., 2007) results from the first Monte Carlo simulation of the subsurface Martian radiation environment for several pertinent scenarios. The findings included, among others, the prediction of a 450000 year survival time of a radioresistant population at $2 \mathrm{~m}$ depth (the maximum drill depth of ExoMars; Vago et al., 2006) in permafrost-laden regolith and an excavation of at least $7.5 \mathrm{~m}$ to be necessary to recover viable cells cryopreserved within the putative Cerberus pack-ice (Murray et al., 2005).

Now we continue this research into the question of persistence times of particular organic molecules. Life may perhaps have fallen extinct in the near subsurface, but would still betray its prior existence by the presence of distinctive biogenic organic molecules. Assuming a Martian biochemistry convergently similar to the terrestrial system (or perhaps even a shared ancestry through cross-fertilisation by lithopanspermia between our two planets; Melosh, 1988; Moreno, 1988; Mileikowsky et al., 2000), such biomarkers would include DNA and proteins, or their component nucleobases and amino acids respectively, or other cellular break-down products such as hopanoids (Simoneit et al., 1998). Many astrobiological instruments designed for recent or coming Mars landers are based on the detection of such biomarker molecules.

Here, we model the dose-depth profile of the Martian subsurface in order to allow the theoretical or experimental determination of persistence times of such biomarkers.

\subsection{Optically Stimulated Luminescence}

Another important application for modelling the Martian radiation environment is in calculating the rate of dose accumulation by the rock itself. Optically Stimulated Luminescence (OSL) is a technique able to provide accurate, and absolute, measurements of the period since sediments were last exposed to sunlight (i.e. their time of deposition) (Doran et al., 2004). The energy deposited by ionising radiation in suitable minerals, such as quartz and feldspar, creates free electrons trapped within the crystal lattice. Subsequently stimulating 
the exposed samples with light releases the stored energy as luminescence, a signal that is proportional to the radiation dose absorbed since burial (Doran et al., 2004). Thus certain minerals act as a natural dosimeter, and the accumulated dose can be read by an instrument suitable for inclusion in a Martian lander (McKeever et al., 2003). The absolute age of the sediment is given as the ratio of total absorbed radiation dose (Gy) to the local dose accumulation rate $\left(G y y^{-1} \mathrm{r}^{-1}\right.$ ). Using this to date formation of a sediment layer assumes that the grains had been sufficiently exposed to light, thus resetting the dosimetry "clock", at the time of deposition; an assumption likely to be true for the aeolian-dominated deposition and high UV-flux of modern Mars (McKeever et al., 2006).

Using the luminescence signal to accurately date the sediment requires knowledge of both the dose accumulation rate in the local environment and the OSL properties of the mineral. The significant exclusion of SEP and GCR from the Earth's surface by the geomagnetic field and dense terrestrial atmosphere means that the major source of ionising radiation is from decay of radionuclides in the surrounding rock itself. On the Martian surface, however, ionisation from SEP and GCR cascades will dominate, and calculating the dose accumulation rate as a function of depth, under different scenarios, and its variability over time, is vital in calibrating this potentially crucial dating technique. We present such modelling data here, calculating dose-depth profiles from GCR under varied scenarios.

\section{Method}

This research employs Geant4 (Agostinelli et al., 2003) to perform a Monte Carlo (MC) simulation of the entire secondary cascades within a full 3-D environment, allowing a precise specification of the geometry, atmospheric and regolithic spatial heterogeneity, reproduction of particle scattering and the actual isotropic angular distribution of incoming primary particles. The Geant 4 code has been validated against experimental data (Beringer et al., 2003; Amako et al., 2005), and the specific physics description used in this study, derived from PLANETOCOSMICS, performs well in calculating particle fluxes as a function of altitude in the terrestrial atmosphere (Desorgher et al., 2005).

The model comprises a $70 \mathrm{~km}$ atmospheric column atop $20 \mathrm{~m}$ of surface material. The layered atmosphere allows accurate reproduction of any desired scenario in terms of composition and pressure, density and temperature profiles, and the surface composition and density can likewise be rapidly reconfigured. Unless otherwise specified, data on the current atmosphere is taken from the Mars Climate Database (http: //www-mars.lmd.jussieu.fr/) to represent noon on a Summer day $(\mathrm{Ls}=270-300)$ within Arabia Terra. This season represents the annual peak for atmospheric density, and the location selected as it lies at the reference altitude with a surface pressure of 6 mbar.
GCR primary spectra for $Z=1-26$ (protons to iron nuclei) are taken from the CREME96 model (https://creme96.nrl. navy.mil/) for solar minimum and maximum conditions, and extrapolated to $1 \mathrm{TeV} /$ nucleon with a power-law exponent of -2.65 . In general, the simulations reported here have used data collected from proton primaries, which are then weighted by energy integration to account for all GCR spectra (a factor we calculated from the CREME96 model to equal 1.37 under solar minimum and 1.42 under maximum conditions). These primary spectra, which range from $10^{2}-$ $10^{6} \mathrm{MeV} /$ nuc, are divided into four sections spanning one order of magnitue of energy each, as shown in Fig. 1, with each section being simulated in turn and data then collated. Primaries are sampled from the spectral section, and fired one-at-a-time with an isotropic angular spread down through the atmospheric and surface column. The propagation of all particles are tracked, with a full treatment of physical interactions and particle decays within the secondary cascades. All energy deposition events in the ground are logged, and binned into $5 \mathrm{~cm}$-thick layers to produce a fine-detail dose-depth profile through the Martian subsurface. Figure 3 presents a visualisation of the model set-up, with an energetic GCR primary striking the Martian surface to initiate an extensive subsurface secondary cascade.

Four distinct sets of simulations, representing changes to the most important parameters, are reported here:

(1) Properties of the surface material, in terms of composition and density. Elemental composition was modified to create three distinct scenarios: a) Martian rock with elemental proportions taken as the mean of Pathfinder analyses of soil samples (Wänke et al., 2001) at either $1 \mathrm{~g} / \mathrm{cm}^{3}$ for dry dust or $3 \mathrm{~g} / \mathrm{cm}^{3}$ to represent denser regolith; b) $1 \mathrm{~g} / \mathrm{cm}^{3}$ pure water ice used to emulate environments such as the north polar ice cap, frozen crater lakes or the putative Cerberus pack-ice (Murray et al., 2005); and c) a layered model of permafrost-containing regolith, stratified into a $25 \mathrm{~cm}$ layer of $1.1 \mathrm{~g} / \mathrm{cm}^{3}$ topsoil $2 \%$ water by weight, a $75 \mathrm{~cm}$ thick layer of $1.1 \mathrm{~g} / \mathrm{cm}^{3}$ topsoil with $16 \%$ water, and the bottom $19 \mathrm{~m}$ as $3 \mathrm{~g} / \mathrm{cm}^{3}$ regolith with $16 \%$ water. This layering reproduces the model of subsurface permafrost in Arabia Terra based on neutron backscatter data (Mitrofanov et al., 2004), but is also a good approximation of ice-laden regolith in high latitudes. The elemental compositions of topsoil and regolith strata were taken as the Pathfinder average soil and calculated soil-free rock (Wänke et al., 2001) respectively, although previous studies have found the exact elemental composition to have negligible effect on the shielding properties of regolith (Kim et al., 1998). In all these simulations, the GCR spectra during solar minimum were taken to represent a worse-case scenario.

(2) Variation of the impingent GCR primary radiation spectrum, from the worst-case scenario during solar activity cycle minimum to maximum heliosphere modulation of the GCR flux, as shown in Fig. 1. In this modelling set, as well as those of simulations (3) and (4) below, the surface 


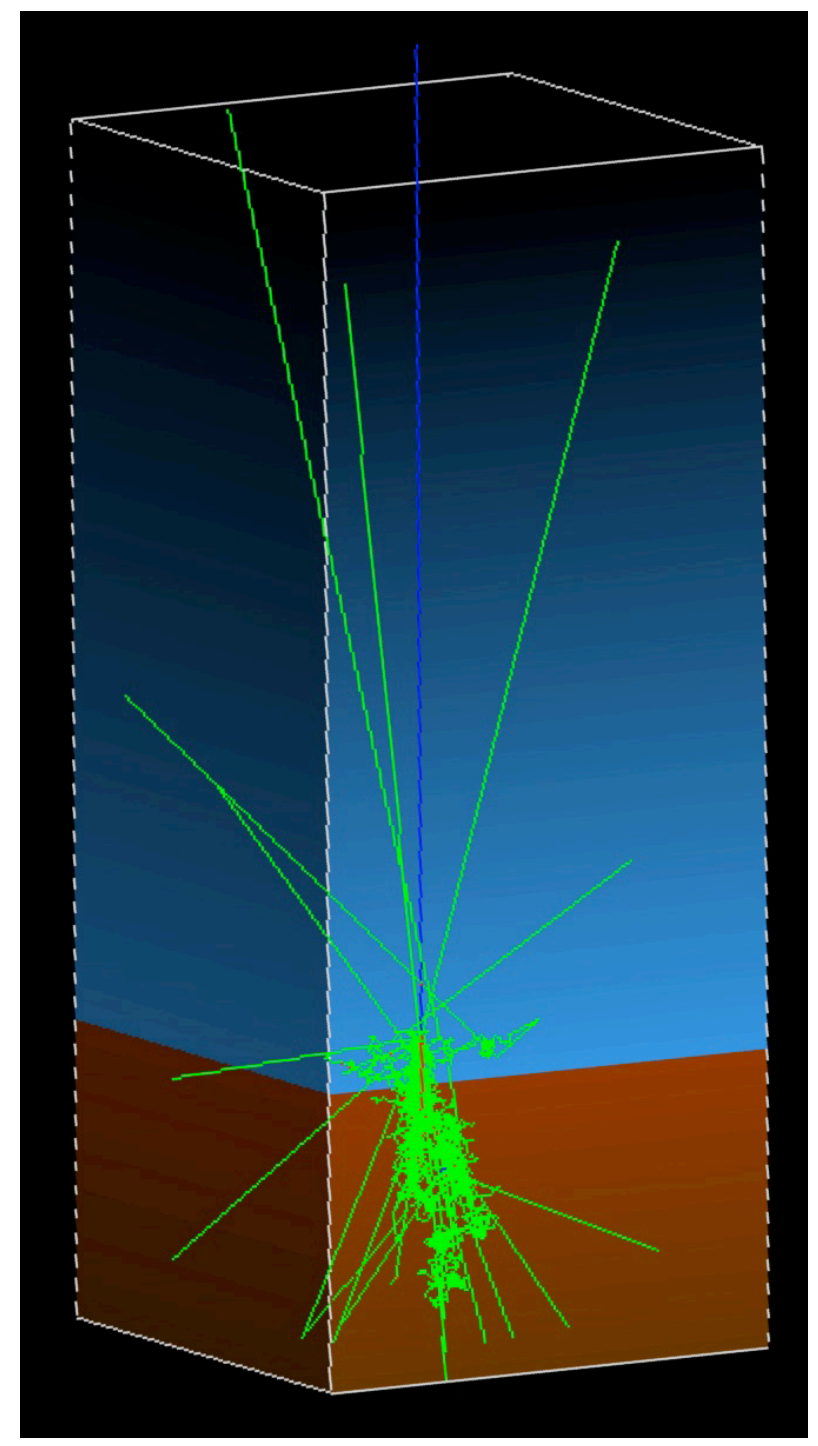

Fig. 3. Visualisation of the model set-up, showing the extensive subsurface secondary cascade generated by a single energetic primary GCR ion from directly above.

material is set as $1 \mathrm{~g} / \mathrm{cm}^{3}$ dry dust as this allows simple conversion between units of true depth $(\mathrm{cm})$ and shielding depth $\left(\mathrm{g} / \mathrm{cm}^{2}\right)$.

(3) Effect of topographic elevation on the subsurface dose profile. Mars exhibits the greatest topographic extremes of any body in the solar system, with roughly a $34 \mathrm{~km}$ difference between the bottom of the Hellas impact basin and the peak of Olympus Mons. Here we calculate the subsurface dose-profile in $1 \mathrm{~g} / \mathrm{cm}^{3}$ dry dust at elevations between these two extremes, and also with the atmosphere set to vacuum to study its contribution to the surface dose. The atmospheric column above each location was modelled using the technique explained below in part (4).
(4) Decreasing shielding thickness of the Martian atmosphere over geological history. The current Martian atmosphere creates a surface pressure of 6 mbar at the datum altitude. Geomorphological evidence for a warmer wetter primordial Mars indicates that a previously much thicker atmospheric column has eroded away over time through processes such as pick-up-ion sputtering, hydrodynamic removal, impact erosion, and chemical reactions with the crust (reviewed recently by Jakosky and Phillips, 2001). The cosmic radiation reaching the surface would have increased over geological time as the atmospheric shielding diminished, and so calculations of the subsurface dose profile under different atmospheric pressures are important for estimating long-term biomarker persistence. Although both the primordial atmospheric pressure possessed by Mars and the time course of its erosion are difficult to constrain (Jakosky and Phillips, 2001), the shielding effects of different atmospheric columns can be calculated, even if the absolute time they correspond to is dependent on the particular atmospheric history model. Equation (1) was used to model primordial atmospheres:

$P=P_{0} \cdot \exp \left(-z / z_{1}\right)$

where $P=$ pressure at the given altitude, $P_{0}=$ the surface pressure, $z=$ altitude, and $z_{1}$ is the scale height of the Martian atmosphere, calculated to be currently $10.7 \mathrm{~km}$ using:

$z_{1}=k . T / g . M$

where $k=$ the Boltzmann constant, $T=$ the characteristic temperature of the Martian atmosphere (taken here to be currently $210 \mathrm{~K}), g=$ the gravitational field strength of Mars, and $M=$ average molecular mass of the atmosphere (taken here to be pure $\mathrm{CO}_{2}$ ). The Ideal Gas Equation can then be used to calculate the density profile as a function of the above pressure profile and characteristic temperature. Even though the temperature is not constant through the atmosphere, these exponential functions still provide a good atmospheric approximation. In any case, in terms of modelling radiation propagation the exact density and pressure profiles are much less important than the overall shielding thickness. Figure 4 plots the density profiles calculated using the above method for primordial scenarios with surface pressures of $0.01 \mathrm{bar}$ $\left(27 \mathrm{~g} / \mathrm{cm}^{2}\right), 0.1 \mathrm{bar}\left(268 \mathrm{~g} / \mathrm{cm}^{2}\right)$ and $0.385 \mathrm{bar}\left(1033 \mathrm{~g} / \mathrm{cm}^{2}\right)$. This 0.385 bar scenario was chosen as it produces an atmosphere with a shielding depth of $1033 \mathrm{~g} / \mathrm{cm}^{2}$, equivalent to the current terrestrial atmosphere.

A denser atmosphere would produce a higher temperature through improved efficiency of the greenhouse effect, but to what extent is very poorly constrained as the greenhouse mechanisms that operated throughout Martian history are unknown (e.g., Forget and Pierrehumbert, 1997; Haberle, 1998). Assuming an additional warming of $10 \mathrm{~K}$ for a 0.385 bar atmosphere, we plot the calculated density profile in Fig. 4, along with the profiles produced by $\pm 20 \mathrm{~K}$ limits. The scale height is recalculated in each case, but does not change substantially as it varies linearly with temperature. 


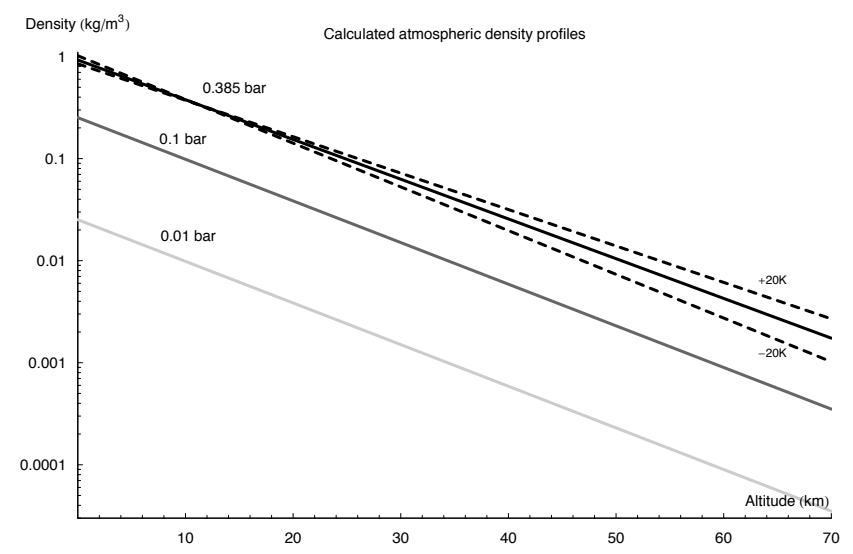

Fig. 4. Altitude-density profiles of the calculated atmospheres. Temperature sensitivity ( $\pm 20 \mathrm{~K}$ limits) also shown for 0.385 bar primordial case.

As can be seen, the density profile is not overly sensitive to changes in characteristic temperature. Furthermore, the shielding depth (the integral under the density curve) of these $\pm 20 \mathrm{~K}$ atmospheres differs by less than $0.1 \%$ from the calculated $1033 \mathrm{~g} / \mathrm{cm}^{2}$ at $220 \mathrm{~K}$. Thus, in terms of attenuating impingent cosmic radiation, the atmosphere models used here are robust to changes in parameters.

\section{Results}

\subsection{Verification of results}

The first simulation performed was to check that the common approximation (the superposition model)(KlapdorKleingrothaus and Zuber, 2000) of using weighted proton $(Z=1)$ data robustly reproduces the dose-profile created by the complete spectra of all GCR ions $(Z=1-26)$. The model was set-up with a $16 \mathrm{~g} / \mathrm{cm}^{2}$ atmosphere, $3 \mathrm{~g} / \mathrm{cm}^{3}$ dry dust surface and solar minimum GCR flux. Firstly, the subsurface dose-profile was calculated by simulating only GCR protons and weighting these results by a factor of 1.37 (see Method) to account for all GCR ions. Integrated from the CREME96 model, proton primaries deliver $73 \%$ of the total GCR energy, He ions a further $19 \%$, and all heavier ions combined contribute the remaining $8 \%$. A second simulation was run with helium and carbon primaries and the data energy-weighted to approximate for heavier ions $(Z=2-26)$ up to $10 \mathrm{GeV} /$ nuc (a light ion modelling limit imposed by Geant4), and proton data filling in for energies between this ceiling and $1 \mathrm{TeV} /$ nuc. These two simulations, weighted proton-only data and weighted proton, $\mathrm{He}$ and $\mathrm{C}$ data, are compared in Fig. 5. As can be seen, the additional processing demand of generating $\mathrm{He}$ and $\mathrm{C}$ data is not required, as the two simulations produce results differing by only $3 \%$ in the top $500 \mathrm{~g} / \mathrm{cm}^{2}$. This is not a significant effect as there is

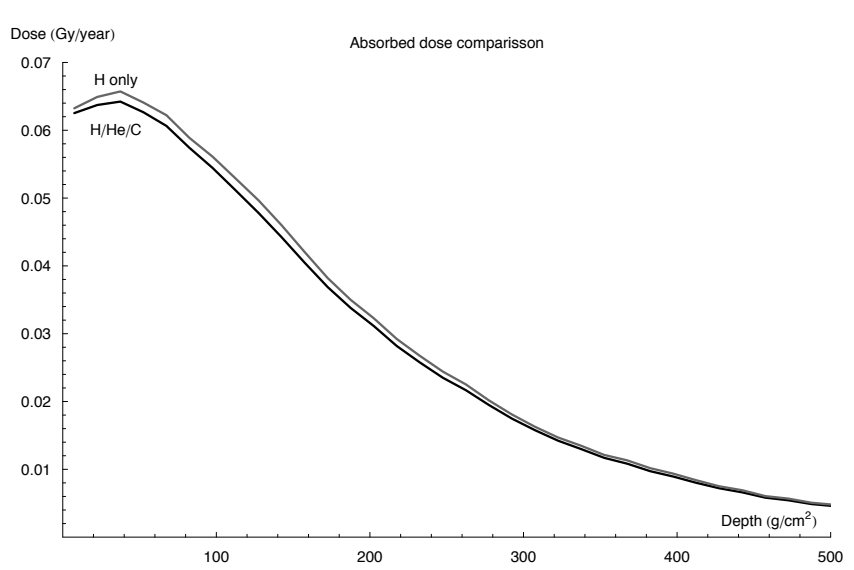

Fig. 5. Comparison of dose profile created by all GCR primaries approximated by weighted $\mathrm{H}$ only data and combined $\mathrm{H} / \mathrm{He} / \mathrm{C}$ data.

greater variance within different models of the GCR spectra and high-energy physics models, and the subsequent use of the proton-only approximation is thus justified.

Using these model parameters, we calculate the current Martian surface dose to be $6.2 \mathrm{cGy} /$ year, building to a peak of $6.6 \mathrm{cGy} /$ year at $40 \mathrm{~g} / \mathrm{cm}^{2}$ shielding depth. These figures agree well with those presented in McKeever et al. (2003), but differ from two other studies into the Martian subsurface radiation dose. Pavlov et al. (2002) report values of a peak dose of $20 \mathrm{cGy} /$ year at $25 \mathrm{~g} / \mathrm{cm}^{2}$ depth and Mileikosky et al. (2000) find a surface dose of $19.4 \mathrm{cGy} /$ year, building to a peak of $24.9 \mathrm{cGy} /$ year at $30 \mathrm{~g} / \mathrm{cm}^{2}$ depth. These two sets of results differ from each other by a factor of approximately 3 , suggesting that the variation is probably due to normalisation of data to the total annual GCR flux.

\subsection{Surface properties}

Figure 6 (top) shows the dose-depth profiles calculated for four distinct surface scenarios: $1 \mathrm{~g} / \mathrm{cm}^{3}$ dry dust, $3 \mathrm{~g} / \mathrm{cm}^{3}$ dry regolith, $1 \mathrm{~g} / \mathrm{cm}^{3}$ water ice, and a layered permafrost model. The dose peak occurs at a shallower depth in the $3 \mathrm{~g} / \mathrm{cm}^{3}$ dry regolith due to it's greater density, but this scales to an equal shielding depth $\left(40 \mathrm{~g} / \mathrm{cm}^{2}\right)$ as the $1 \mathrm{~g} / \mathrm{cm}^{3}$ dry dust surface. The $1 \mathrm{~g} / \mathrm{cm}^{3}$ ice matieral creates a dose peak slightly shallower at $30 \mathrm{~g} / \mathrm{cm}^{2}$ depth. The top meter of loose topsoil of the permafrost model shows a dose intermediate between the dry dust and pure ice models of similar density, and a rapid decline in dose through the higher density ice-laden regolith beneath.

Figure 6 also shows the composition of the ionising radiation field (proportion of dose deposited by different particle species) as it changes with depth. In general the hadronic cascade of HZE and protons is attenuated and the more deeply penetrating (weakly interacting) particles, muons and pions, and the electrons produced in the electromagnetic 

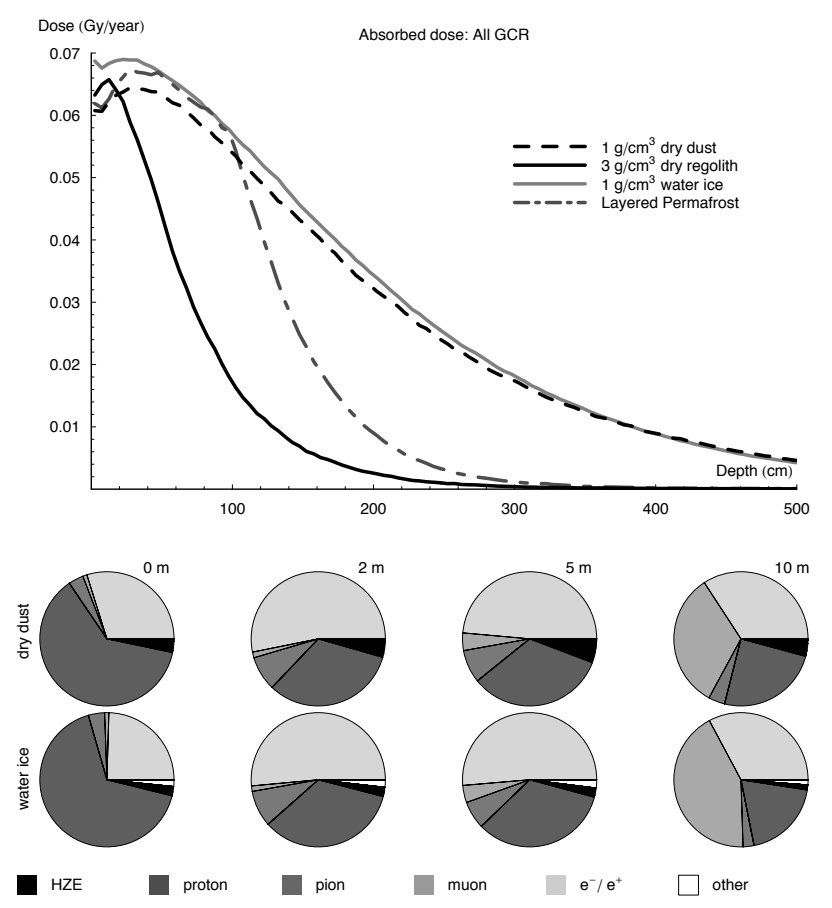

Fig. 6. Top: Dose profiles for different surface scenarios. Bottom: The changing composition of the ionising radiation field with depth, compared between $1 \mathrm{~g} / \mathrm{cm}^{3}$ dry dust and water ice material.

cascade, become increasingly dominant in the radiation environment. At all depths, the HZE dose is lower in the ice material as it contains a much lower compositional proportion of heavy elements and so generates fewer HZE in the hadronic cascade. By $10 \mathrm{~m}\left(1000 \mathrm{~g} / \mathrm{cm}^{2}\right)$ depth the ice shielding material produces a radiation environment with a significantly greater muon contribution. Neutrons, although treated in full by our particle interactions model, are uncharged and do not directly ionise the material, but cause recoiling protons which are highly ionising. This may explain the higher proportion of proton-delivered dose at the surface of the ice; caused by moderation of back-scattering neutrons.

Integration under the dose-depth curve gives the total amount of energy deposited in the surface. The $20 \mathrm{~m}$ depth of dry regolith is found to absorb $73 \%$ of the total energy delivered by the GCR flux (around $0.02 \mathrm{~J} / \mathrm{cm}^{2} /$ year), the rest being absorbed by the atmosphere (5\% of the total) or escaping with back-scattering particles (mostly neutrons and gammas). The pure ice column retains $76 \%$ of the incoming energy, the slight increase presumably due to more effective capture of neutrons by its hydrogenous content (most significantly the backscattering neutrons, creating the higher dose observed on the surface).

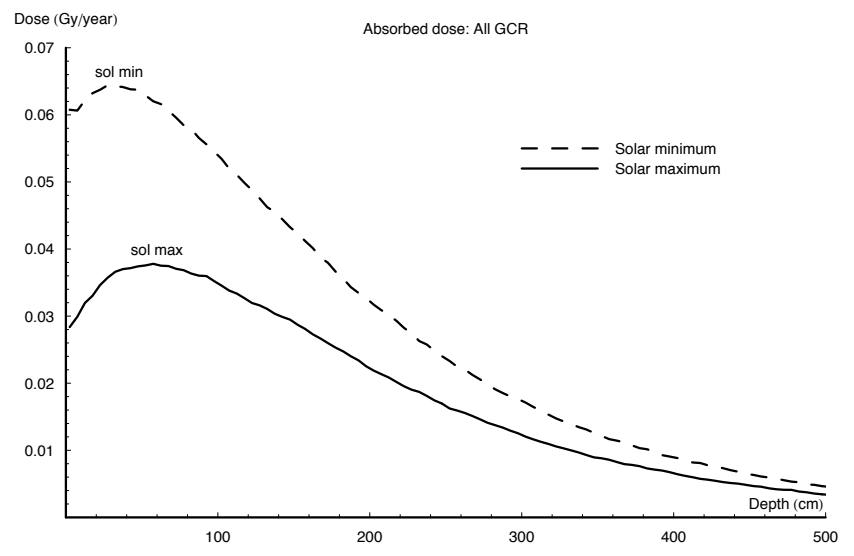

Fig. 7. Subsurface dose profiles under solar activity maximum and minimum conditions.

\subsection{Primary radiation spectra}

Figure 7 shows the calculations when irradiating the model with the CREME96 spectra for either solar minimum or solar maximum conditions. The surface and peak dose during solar minimum can be seen to be about double that of solar maximum. Integrated over the entire $20 \mathrm{~m}$ depth, the dose deposited during solar maximum is only two-thirds that of minimum activity conditions. Furthermore, the peak dose during solar maximum, although less in magnitude, occurs $20 \mathrm{~g} / \mathrm{cm}^{2}$ deeper in the surface.

These are all effects of the significant heliospheric modulation of primaries $\lesssim 10 \mathrm{GeV} /$ nuc during periods of solar maximum. As seen in Fig. 1, there is an order of magnitude difference in flux for $100 \mathrm{MeV}$ primary protons, and still a modulation factor of 3.6 at $1 \mathrm{GeV}$. Figure 8 shows the dose contribution from the different energy bands of the GCR proton spectrum at solar minimum, with the section numbers corresponding to the ranges indicated in Fig. 1.

Several important features are evident here. Protons $<1 \mathrm{GeV}$ (energy section 1) produce no dose peak; their profile is a simple exponential decay. The primaries do not carry enough kinetic energy for collisions to generate a hadronic cascade and they are quickly attenuated by the shielding matter. Each higher energy segment of the proton spectrum produces a deeper peak. Section $4(100 \mathrm{GeV}-1 \mathrm{TeV})$ produces a gentle peak at $1.3 \mathrm{~m}$ depth, three times deeper than section 2 primaries, but due to the very low flux of such high energy primaries this section does not contribute a large proportion of the total annual dose. The most important energy band of the primary spectrum is section 2 as it combines a high flux with relatively energetic particles. Shown in Fig. 8, this energy range $(1 \mathrm{GeV}-10 \mathrm{GeV})$ deposits over half of the total dose in the subsurface. These primaries are significantly modulated by the heliosphere between solar maximum and minimum phases (Fig. 1), and so the solar activity cycle is 


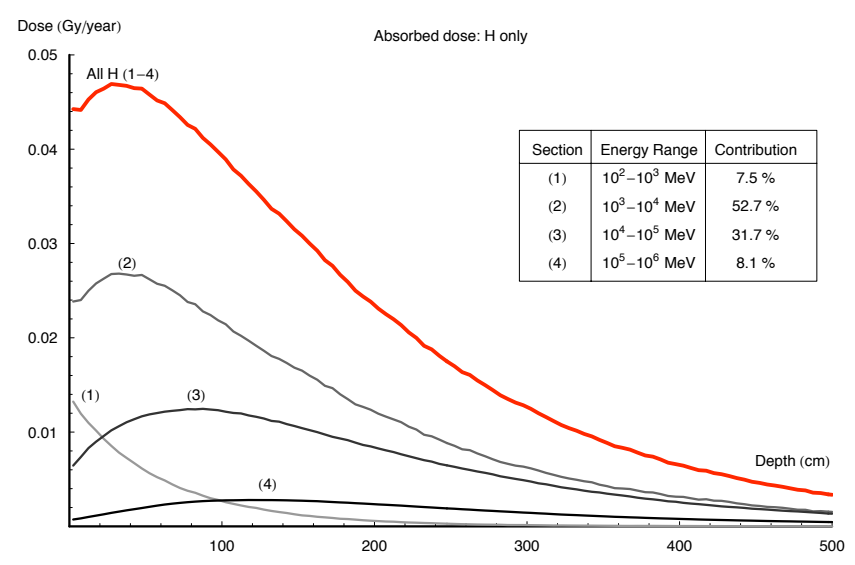

Fig. 8. Dose contributions from different energy bands of the primary GCR proton spectrum. Section numbers correspond to the energy ranges indicated in Fig. 1.

manifested in the changing subsurface dose profile (shown in Fig. 7) principally through modulation of primary protons in the energy band $1 \mathrm{GeV}-10 \mathrm{GeV}$ (section 2 in this model).

\subsection{Topographic elevation}

Figure 9 plots the dose profiles for three characteristic elevations on Mars (Olympus Mons, Hellas basin, and the datum altitude) as well as a null atmosphere. The general trend across the four scenarios of increasing atmospheric thickness is decreasing peak dose at a shallower depth beneath the surface.

Even though the Martian atmosphere is comparatively thin, providing only 6 mbar surface pressure at the reference altitude, it can be seen that its radiation shielding properties should not be discounted. Comparrison of the dose profile at the datum altitude against that beneath vacuum indicates that even a $16 \mathrm{~g} / \mathrm{cm}^{2}$ depth of atmosphere affects cosmic ray propagation. Perhaps paradoxically, the effect of this additional shielding is to actually increase the surface dose by $10 \%$ through limitted initiation of secondary cascades. At the lower elevation of the Hellas basin, the surface dose is lower again as the doubled atmospheric shielding thickness begins to exert an attenuation effect. Beneath about a meter's subsurface depth, the dose profiles for Olympus Mons, datum altitude and Hellas basin roughly follow each other but for a $\sim 16 \mathrm{~g} / \mathrm{cm}^{2}$ shift in depth, and by $5 \mathrm{~m}$ depth, variation in atmospheric thickness has negligible remaining effect.

\subsection{Diminishing atmospheric pressure over geological time}

Figure 10 plots the subsurface dose profiles under four surface pressure scenarios $\left(0.385 \mathrm{bar}, 1033 \mathrm{~g} / \mathrm{cm}^{2} ; 0.1 \mathrm{bar}\right.$, $268 \mathrm{~g} / \mathrm{cm}^{2}$; 0.01 bar, $27 \mathrm{~g} / \mathrm{cm}^{2}$; 0.006 bar, $\left.16 \mathrm{~g} / \mathrm{cm}^{2}\right)$. This sequence of diminishing atmospheric thickness is taken to represent gaseous loss over the geological history of the planet,

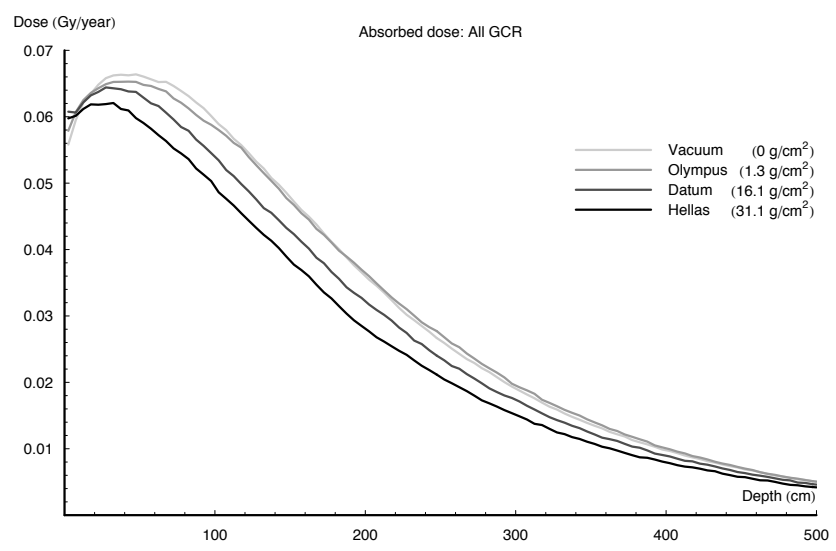

Fig. 9. Subsurface dose profiles for locations with different elevations on Mars.

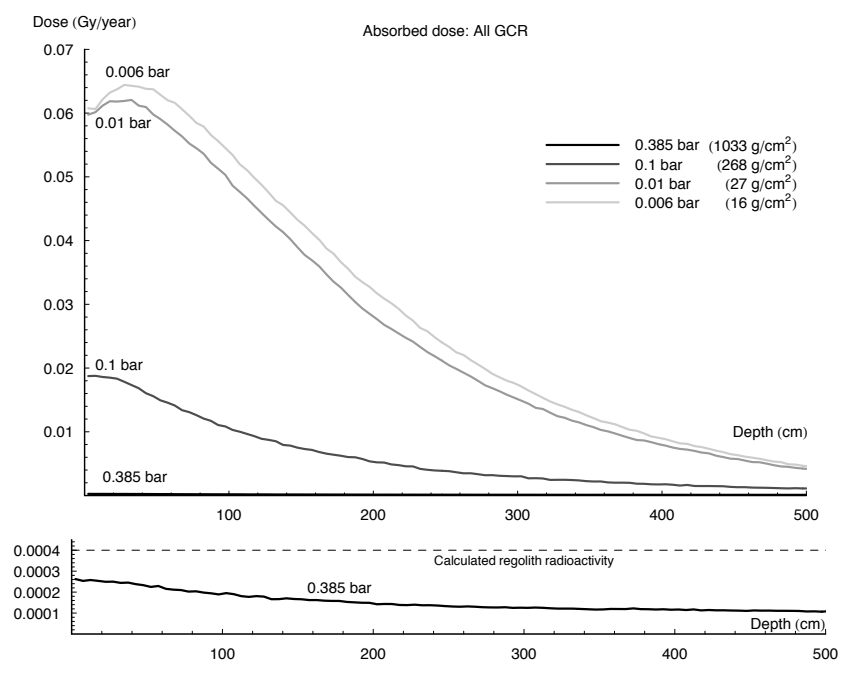

Fig. 10. Subsurface dose profiles under decreasing atmospheric depths, over the geological history of Mars. Rescaled plot of 0.385 bar case shown below.

independent of models attempting absolute dating of these stages.

Decreasing surface pressure produces a non-linear response of total atmospheric shielding thickness (integration of the density-altitude profile), and thus also of generated subsurface dose profile. Scaling with the combined shielding thickness of atmosphere and subsurface, however, the surface dose under a 0.385 bar atmosphere is roughly equivalent to that at $10 \mathrm{~m}$ depth with the current atmosphere, and the surface dose under a 0.1 bar atmosphere equivalent to $2.4 \mathrm{~m}$ depth with 0.01 bar atmosphere.

Figure 10 also shows a replot of the subsurface dose profile beneath a 0.385 bar atmosphere (which produces an identical shielding depth to the current 1 bar terrestrial atmosphere) 
on an expanded scale. The surface dose, deposited almost entirely by muons and electrons, is $2.6 \times 10^{-4} \mathrm{~Gy} /$ year, less than the calculated $4 \times 10^{-4} \mathrm{~Gy} /$ year contribution from natural radioactivity of the regolith (Mileikowsky et al., 2000), and so the biological effects of GCR are not significant beneath such a dense atmosphere.

\section{Discussion}

\subsection{Preservation of astrobiological markers}

Exposure of biological macromolecules, such as carbohydrates, nucleic acids and proteins, to ionising radiation is known to cause both fragmentation and aggregation (Hutchinson, 1963). For protein irradiation under Martian conditions of low temperature frozen aqueous solutions, fragmentation through breakage of the polypeptide backbone is the major damage observed (Filali-Mouhim et al., 1997). Filali-Mouhim et al. (1997) have found that $70 \mathrm{kGy}$ of radiation (corresponding to $1.3 \mathrm{Myr}$ exposure beneath a meter of dry dust in our model) is sufficient to shatter lysozyme into at least 11 small fragments. The molecular masses of enzymes have long been approximated by irradiation in aqueous solution or as a lyophilized (freeze-dried) powder (Nugent, 1986). The remaining biological activity of an irradiated sample of enzymes decreases exponentially with the absorbed dose, and assuming that the activity of each individual polypeptide is destroyed by a single hit (primary ionisation) the decay constant can been used to calculate the target molecular mass. Pavlov et al. (2002) have used a similar formula to estimate the part of molecular bonds broken in a macromolecule of given molecular mass as a function of absorbed dose, and find that total degradation of macromolecules in the top Martian subsurface occurs in $10^{8}-10^{9}$ years. However, there is increasing evidence that protein radiolysis is dependent not on molecular mass but the solventaccessible surface area, explaining the observation of preferential cleavage on solvent-exposed loops and that denatured proteins fragment to a much greater extent than native ones (Filali-Mouhim et al., 1997; Audette et al., 2000). Furthermore, such a calculation for complete destruction may overestimate the relevant persistence time, as a macromolecule may not need to be extensively radiolytically modified to escape detection by a biomarker detection instrument designed to identity specific molecules.

In another attempt to gauge biomolecule survival in the Martian subsurface radiation environment, Kminek and Bada (2006) use previously-published dose-depth calculations (Mileikowsky et al., 2000) with their experimental results on gamma irradiation of dry amino acids. We, however, find lower dose rates in the Martian subsurface than reported by Mileikowsky et al. (2000), yet consistent with other research in the literature. These results are presented here for use in scaling experimental irradiations to the dose rates at different depths and locations on Mars. Advances of this modelling effort over previous astrobiological studies (e.g., Mileikowsky et al., 2000; Pavlov et al., 2002) include analysis of variation in atmospheric depth and composition of the subsurface. Most crucial is the permafrost content of the regolith; water is an effective neutron moderator, and as shown in Fig. 6 ground ice creates a significant dose enhancement in the near subsurface.

An important consideration in estimating the radiolytic degradation rates of biosignature macromolecules is the dependence on the LET of the ionising particles. The dense ionisation tracks of high-LET protons and HZE ions produce complex clusters of breaks in DNA that is of a lower cellular reparability than sparse gamma-induced damage and thus has more severe consequences for survival (Goodhead, 1999). This disproportionate hazard of high-LET particles can be taken into account by weighting the physical absorbed dose by a relative biological effectiveness (RBE) factor, dependent on the responsible particle type and energy, appropriate for cell death (e.g., Pavlov et al., 2002; Dartnell et al., 2007). The relationship between LET and biosignature degradation is less clear, however. For example, Butts and Katz (1967) find that the RBE of heavy ions for degradation of dry enzymes and viruses is in fact less than unity, meaning that they are less effective than low-LET radiation due to depositional saturation. On a smaller scale, that of amino acid or nucleobase destruction, there is no reason to expect the spatial pattern of HZE ionisation to have a significant effect at all, and Malinen et al. (2003) find that the radiolysis of alanine is not LET-dependent.

There is an additional factor that may prove to be significant to the relative importance of low- or high-LET particle irradiation under the current Martian subsurface conditions of very low temperature ice. Radiolysis of biomolecules occurs through both direct and indirect mechanisms; ionisation from a particle hit (dominant in dry irradiation) and attack from diffusible free radicals generated by the radiolysis of water (dominant in dilute aqueous solution), respectively (Hutchinson, 1963). Subsurface Martian permafrost is intermediate to these extremes and so both direct and indirect radiolysis will be important. Radiosensitivity is known to decrease with lower temperature because of the reduced diffusion of radicals, and $\mathrm{OH}$. and $\mathrm{O}_{2} \mathrm{H}$. become immobile below $135 \mathrm{~K}$ and $\mathrm{H}$. radicals below $77 \mathrm{~K}$ (Horneck, 2005). The yield of single radicals from high-LET particles is lower, however, due to recombination within the dense ionisation track, and such radiation produces higher proportions of molecular oxidants such as $\mathrm{H}_{2} \mathrm{O}_{2}$ (Goodhead, 1999) which are even less mobile at low temperatures.

A further implication of radiolytic degradation on the detectability of biosignatures is that it will be difficult to distinguish between break-down debris of large biomolecules, a valid signature of extinct or extant life, and the simple abiotic chemical species created in situ by prebiotic chemistry or exogenously-delivered by meteoritic or cometary in-fall. 
Certain organic molecules, however, may represent robust evidence of a biogenic origin, rather than abiotic chemistry, despite their small size. Chemical species such as nucleosides are not believed to be synthesised in great proportions by prebiotic chemistry (Orgel, 2004); indeed their crucial status in terrestrial biochemistry is something of a paradox in the origin of life. Other small species are accepted as unambiguous molecular fossils in terrestrial deposits, such as hopanes from the breakdown of oxygenic photosynthetic cyanobacteria and steranes from eukaryotic and some bacterial cell membranes (although the synthesis of sterols requires $\mathrm{O}_{2}$ in all known terrestrial organisms, and so may not be expected in Martian biota) (Simoneit et al., 1998).

Another potential biosignature of great interest is that many organic molecules used by terrestrial life are selectively of a single enantiomer, whereas laboratory experiments into prebiotic chemistry produce no such pronounced bias (Bada and Miller, 1987), and most of the extraterrestrial amino acids isolated from the Murchison meteorite are racemised (Engel and Nagy, 1982). Many researchers therefore believe that if organics found on Mars were to show a distinct enantiomer bias this would constitute a robust biosignature. Surviving amino acids in a partially-radiolysed sample, however, have been found to show a degree of radioracemisation (Bonner, 1999, and references to earlier work therein), and thus removal of this chirality biomarker. Even if amino acids are isolated in the Martian subsurface, survivors of oxidation and ionisation, the un-radiolysed fraction may exhibit enough radioracemisation to not be readily identifiable as biogenic.

Our modelled unweighted physical dose-depth curves under a variety of different scenarios are presented here for the use of laboratory experimentation into the persistence of various biomarkers in the ionising radiation environment of the Martian near-subsurface. As explained above, there are important considerations of the radiation field on the potential detectability of biosignatures on the Martian surface, and the model described here can be rapidly adapted to incorporate new experimental data on the LET- or temperaturedependence of radiolytic biosignature degradation.

\subsection{OSL dating}

The upper limit on OSL dating is determined by saturation of the luminescence signal, an effect due to the finite number of traps within the material, and generally occurs with a total dose on the order of several kGy (McKeever et al., 2003). The temporal limit for Martian sediments may vary much more than on Earth. The high ionisation rate just beneath the surface from unshielded GCR will produce rapid saturation, but due to the assumed lower incidence of radioisotopes in the Martian surface, sediments rapidly buried to depths greater than several meters will experience a dose rate less than on Earth and so the maximum dating limit may be extended (Doran et al., 2004). Jain et al. (2006) report the measured saturation dose of different minerals to range between $2 \mathrm{kGy}-30 \mathrm{kGy}$, which gives a maximum dating limit of 30000-460000 years for rapid burial beneath $30 \mathrm{~cm}$ of dry dust, increasing to $~ 400000-6$ million years at $5 \mathrm{~m}$ depth, from our radiation model. This agrees with the estimation of McKeever et al. (2003) for the upper limit for dating Martian sediments at $10^{3}-10^{6}$ years.

Heavy charged particles, with their large LET value, create regions with high ionisation density. This produces local charge saturation effects, and consequently the OSL response for a given dose deposited by HZE is lower than that from low-LET radiation such as energetic electrons or gammas. Thus, the response to weakly ionising and densely ionising particles, such as gamma rays and heavy ions respectively, is opposite in organism survival and OSL of sediments. Without taking into account this LET-dependent variation in OSL efficiency, the simple dose rate will overestimate effective value (Jain et al., 2006). However, the exact dependence of OSL efficiency on LET needs to be experimentally-determined for different particle species and each dosimeter material likely to be encountered on Mars. When such experimental data becomes available (e.g. Jain et al., 2006), these efficiency functions can be readily incorporated into our particle transport model to produce more refined calibrations suitable for Martian OSL dating.

The only other direct chronologies for Mars are based on the observed crater density, but this technique has poor temporal resolution and is inaccurate for features younger than about a million years (McKeever et al., 2003). This lower age range is well covered by OSL dating, and thus it forms an essential complementary in situ technique for determining Mars' geomorphological and climatic history. The dose profiles presented here can be employed in the necessary calibration of this dating technique.

\section{Conclusions}

Ionising radiation is known to be hazardous to the survival of cells and spores, as well as the persistence of molecular biomarkers, and so characterising the Martian subsurface radiation environment created by galactic cosmic rays is of prime astrobiological interest. In addition, accurate models of the dose accumulation rate are needed for application of the optically stimulated luminescence technique for dating Martian sediments. Various scenarios have been modelled here, covering parameters of the surface composition, primary radiation spectra, location elevation, and long-term changes in Martian atmospheric depth.

Our calculated dose-depth profiles, as well as the relative contributions from different particle species, are found to be strongly dependent on the shielding material. Although the surface dose is greatest above ice, the subsurface ionisation contribution from HZE flux is reduced. Total subsurface energy deposition is found to vary by $60 \%$ between 
solar maximum and minimum activity conditions, principally through heliospheric modulation of GCR proton flux in the $10^{3}-10^{4} \mathrm{MeV}$ energy band. The current thin Martian atmosphere is also found to be non-negligible for the surface dose, and significant variation found in subsurface doseprofiles for different elevations. Over geological history, the Martian atmospheric density has decreased, with a primordial 0.385 bar column calculated to offer sufficient radiation shielding for the GCR-induced surface dose to be less than that expected from radionuclide emission.

The unweighted absorbed dose calculations presented here provide data applicable to both experimental irradiation research on biosignature degradation and the use of OSL dating on Mars. Other important factors, such as the temperature- or LET-dependence of biosignature degradation or OSL signal can be rapidly incorporated into the model presented here as experimentally-derived values become available.

Edited by: J. Toporski

\section{References}

Acuna, M. H., Connerney, J. E. P., Ness, N. F., Lin, R. P., Mitchell, D., Carlson, C. W., McFadden, J., Anderson, K. A., Reme, H., Mazelle, C., Vignes, D., Wasilewski, P., and Cloutier, P.: Global Distribution of Crustal Magnetization Discovered by the Mars Global Surveyor MAG/ER Experiment, Science, 284, 790-793, 1999.

Agostinelli, S., Allison, J., Amako, K., Apostolakis, J., Araujo, H., Arce, P., Asai, M., Axen, D., Banerjee, S., Barrand, G., Behner, F., Bellagamba, L., Boudreau, J., Broglia, L., Brunengo, A., Burkhardt, H., Chauvie, S., Chuma, J., Chytracek, R., Cooperman, G., Cosmo, G., Degtyarenko, P., Dell'Acqua, A., Depaola, G., Dietrich, D., Enami, R., Feliciello, A., Ferguson, C., Fesefeldt, H., Folger, G., Foppiano, F., Forti, A., Garelli, S., Giani, S., Giannitrapani, R., Gibin, D., Cadenas, J. J. G., Gonzalez, I., Abril, G. G., Greeniaus, G., Greiner, W., Grichine, V., Grossheim, A., Guatelli, S., Gumplinger, P., Hamatsu, R., Hashimoto, K., Hasui, H., Heikkinen, A., Howard, A., Ivanchenko, V., Johnson, A., Jones, F. W., Kallenbach, J., Kanaya, N., Kawabata, M., Kawabata, Y., Kawaguti, M., Kelner, S., Kent, P., Kimura, A., Kodama, T., Kokoulin, R., Kossov, M., Kurashige, H., Lamanna, E., Lampen, T., Lara, V., Lefebure, V., Lei, F., Liendl, M., Lockman, W., Longo, F., Magni, S., Maire, M., Medernach, E., Minamimoto, K., de Freitas, P. M., Morita, Y., Murakami, K., Nagamatu, M., Nartallo, R., Nieminen, P., Nishimura, T., Ohtsubo, K., Okamura, M., O’Neale, S., Oohata, Y., Paech, K., Perl, J., Pfeiffer, A., Pia, M. G., Ranjard, F., Rybin, A., Sadilov, S., Di Salvo, E., Santin, G., Sasaki, T., Savvas, N., Sawada, Y., et al.: GEANT4 - A simulation toolkit, Nuclear Instruments and Methods In Physics Research Section A - Accelerators Spectrometers Detectors And Associated Equipment, 506, 250-303, iSI Document Delivery No.: 696WP, 2003.

Amako, K., Guatelli, S., Ivanchenko, V. N., Maire, M., Mascialino, B., Murakami, K., Nieminen, P., Pandola, L., Parlati, S., Pia, M. G., Piergentili, M., Sasaki, T., and Urban, L.: Comparison of
Geant4 Electromagnetic Physics Models Against the NIST Reference Data, Nuclear Science, IEEE Transactions on, 52, 910 918, 0018-9499, 2005

Ambrosi, R. M., Talboys, D. L., Sims, M. R., Bannister, N. P., Makarewicz, M., Stevenson, T., Hutchinson, I. B., Watterson, J. I. W., Lanza, R. C., and Richter, L.: Neutron activation analysis, gamma ray spectrometry and radiation environment monitoring instrument concept: GEORAD, Nuclear Instruments and Methods in Physics Research Section A: Accelerators, Spectrometers, Detectors and Associated Equipment, 539, 198-216, 2005.

Audette, M., Chen, X., Houee-Levin, C., Potier, M., and Maire, M. L.: Protein gamma-radiolysis in frozen solutions is a macromolecular surface phenomenon: fragmentation of lysozyme, citrate synthase and alpha-lactalbumin in native or denatured states, Int. J. Radiation Biol., 76, 673, doi:10.1080/095530000138349, 2000.

Bada, J. L. and Miller, S. L.: Racemization and the origin of optically active organic compounds in living organisms, Biosystems, 20, 21-26, 1987.

Baumstark-Khan, C. and Facius, R.: Life under Conditions of Ionizing Radiation, in: Astrobiology: The Quest for the Conditions of Life, edited by: Horneck, G. and Baumstark-Khan, C., 260283, Springer, 2001.

Beringer, J., Folger, G., Gianotti, F., Ribon, A., Wellisch, J. P., Barberis, D., Cervetto, M., and Osculati, B.: Validation of Geant4 hadronic physics, Nuclear Science Symposium Conference Record, 2003 IEEE, 1, 494, 2003.

Bonner, W. A.: The radiolysis and radioracemization of poly-Lleucines, Radiation Res., 152, 83-87, 1999.

Boston, P. J., Ivanov, M. V., and McKay, P. C.: On the possibility of chemosynthetic ecosystems in subsurface habitats on Mars, Icarus, 95, 300, 1992.

Butts, J. J. and Katz, R.: Theory of RBE for heavy ion bombardment of dry enzymes and viruses, Radiation Res., 30, 855-871, 1967.

Cain, J. C., Ferguson, B. B., and Mozzoni, D.: An n=90 internal potential function of the Martian crustal magnetic field, J. Geophys Res.-Planets, 108, 1-19, 2003.

Carr, M. H.: Water on Mars, Oxford University Press, 1996.

Clark, B. C.: Surviving the limits to life at the surface of Mars, J. Geophys. Res.-Planets, 103, 28 545-28 555, iSI Document Delivery No.: 144AK 0148-0227, 1998.

Close, F., Dudeney, J., and Pounds, K.: Report of the Commission on the Scientific Case for Human Space Exploration, Tech. rep. Royal Astronomical Society, 2005.

Cockell, C. S.: The ultraviolet history of the terrestrial planets - implications for biological evolution, Planet. Space Sci., 48, 203214, 2000a.

Cockell, C. S.: The Ultraviolet Environment of Mars: Biological Implications Past, Present, and Future, Icarus, 146, 343-359, 2000b.

Dartnell, L. R., Desorgher, L., Ward, J. M., and Coates, A. J.: Modelling the surface and subsurface Martian radiation environment: Implications for Astrobiology, Geophys. Res. Lett., 34(2), L02207, doi:10.1029/2006GL027494, 2007.

Desorgher, L., Flückiger, E. O., Gurtner, M., Moser, M. R., and Bütikofer, R.: Atmocosmics: A Geant 4 Code for Computing the Interaction of Cosmic Rays with the Earth's Atmosphere, Int. J. Modern Phys. A, 20, 6802-6804, doi:10.1142/S0217751X05030132, 2005. 
Doran, P. T., Clifford, S. M., Forman, S. L., Nyquist, L., Papanastassiou, D. A., Stewart, B. W., Sturchio, N. C., Swindle, T. D., Cerling, T., Kargel, J., McDonald, G., Nishiizumi, K., Poreda, R., Rice, J. W., and Tanaka, K.: Mars chronology: assessing techniques for quantifying surficial processes, Earth Sci. Rev., 67, 313-337, 2004.

Eidelman, S., Hayes, K. G., Olive, K. A., Aguilar-Benitez, M., Amsler, C., Asner, D., Babu, K. S., Barnett, R. M., and Beringer, J.: 24. Cosmic Rays, in: Review of Particle Physics, vol. 592, p. 1, Phys. Lett. B, 2004.

Engel, M. H. and Nagy, B.: Distribution and enantiomeric composition of amino acids in the Murchison meteorite, Nature, 296, 837, doi:10.1038/296837a0, 1982.

Filali-Mouhim, A., Audette, M., St-Louis, M., Thauvette, L., Denoroy, L., Penin, F., Chen, X., Rouleau, N., Caer, J.-P. L., Rossier, J., Potier, M., and Maire, M. L.: Lysozyme fragmentation induced by gamma-radiolysis, Int. J. Radiation Biol., 72, 63, doi:10.1080/095530097143545, 1997.

Flynn, G. J.: The Delivery of Organic Matter from Asteroids and Comets to the Early Surface of Mars, Earth Moon and Planets, 72, 469-474, 1996.

Forget, F. and Pierrehumbert, R. T.: Warming Early Mars with Carbon Dioxide Clouds That Scatter Infrared Radiation, Science, 278, 1273-1276, 1997.

Formisano, V., Atreya, S., Encrenaz, T., Ignatiev, N., and Giuranna, M.: Detection of Methane in the Atmosphere of Mars, Science, 306, 1758-1761, 2004.

Goodhead, D. T.: Mechanisms for the Biological Effectiveness of High-LET Radiations, J. Radiation Res., 40, S1-S13, 1999.

Haberle, R. M.: Early Mars Climate Models, J. Geophys. Res., 103, 28 467-28 480, doi:10.1029/98JE01396;, 1998.

Hassler, D. M., Wimmer-Schweingruber, R. F., Beaujean, R., Bottcher, S., Burmeister, S., Cucinotta, F., Muller-Mellin, R., Posner, A., Rafkin, S., Reitz, G., and The Rad, T.: The Radiation Assessment Detector (RAD) on the Mars Science Laboratory (MSL), in: COSPAR, Plenary Meeting, p. 2720, 2006.

Hoffman, N.: Modern Geothermal Gradients on Mars and Implications for Subsurface Liquids, in: Conference on the Geophysical Detection of Subsurface Water on Mars, p. 7044, Houston, Texas, 2001.

Horneck, G.: Radiobiological effects at low temperature and their relevance to astrobiology, in: 5th European Workshop on Astrobiology, p. 77, Budapest, Hungary, 2005.

Hutchinson, F.: Radiation Effects on Macromolecules of Biological Importance, Annual Review of Nuclear Science, 13, 535-564, 1963.

Jain, M., Andersen, C. E., Botter-Jensen, L., Murray, A. S., Haack, H., and Bridges, J. C.: Luminescence dating on Mars: OSL characteristics of Martian analogue materials and GCR dosimetry, Radiation Measurements, 41, 755-761, 2006.

Jakosky, B. M. and Phillips, R. J.: Mars' volatile and climate history, Nature, 412, 237, 0028-0836, doi:10.1038/35084184, 2001.

Jaumann, R., Hauber, E., Lanz, J., Hoffmann, H., and Neukum, G.: Geomorphological Record of Water-Related Erosion on Mars, in: Astrobiology: The Quest for the Conditions of Life, edited by: Horneck, G. and Baumstark-Khan, C., Springer, 2001.

Kim, M.-H. Y., Thibeault, S. A., Simonsen, L. C., and Wilson, J. W.: Comparison of Martian Meteorites and Martian Regolith as Shield Materials for Galactic Cosmic Rays, Tech. rep., Lang- ley Research Center, Hampton, Virginia, 1998.

Klapdor-Kleingrothaus, H. and Zuber, K.: Chapter 8: Cosmic Radiation, in: Particle astrophysics, Studies in high energy physics, cosmology, and gravitation, 223-247, Institute of Physics, Bristol, UK, 2000.

Kminek, G. and Bada, J. L.: The effect of ionizing radiation on the preservation of amino acids on Mars, Earth Planet. Sci. Lett., 245(1-2), 1-5, 2006.

Krasnopolsky, V. A.: Some problems related to the origin of methane on Mars, Icarus, 180, 359, 2006.

Malinen, E., Hult, E. A., Holea, E. O., and Sagstuena, E.: Alanine Radicals, Part 4: Relative Amounts of Radical Species in Alanine Dosimeters after Exposure to $619 \mathrm{MeV}$ Electrons and 10 kV-15 MV Photons, Radiation Res., 159, 149-153, 2003.

Masson, P., Carr, M. H., Costard, F., Greeley, R., Hauber, E., and Jaumann, R.: Geomorphologic Evidence for Liquid Water, Space Sci. Rev., 96, 333-364, 2001.

McKeever, S. W. S., Banerjee, D., Blair, M., Clifford, S. M., Clowdsley, M. S., Kim, S. S., Lamothe, M., Lepper, K., Leuschen, M., and McKeever, K. J.: Concepts and approaches to in situ luminescence dating of martian sediments, Radiation Measurements, 37, 527-534, 2003.

McKeever, S. W. S., Kalchgruber, R., Blair, M. W., and Deo, S.: Development of methods for in situ dating of martian sediments, Radiation Measurements, 41, 750-754, 2006.

Melosh, H. J.: The rocky road to panspermia, Nature, 332, 687688, 1988.

Mileikowsky, C., Cucinotta, F. A., Wilson, J. W., Gladman, B., Horneck, G., Lindegren, L., Melosh, J., Rickman, H., Valtonen, M., and Zheng, J. Q.: Natural transfer of viable microbes in space. 1. From Mars to Earth and Earth to Mars, Icarus, 145, 391-427, 0019-1035 Journal Article, 2000.

Mitrofanov, I. G., Litvak, M. L., Kozyrev, A. S., Sanin, A. B., Tret'yakov, V. I., Grin'kov, V. Y., Boynton, W. V., Shinohara, C., Hamara, D., and Saunders, R. S.: Soil Water Content on Mars as Estimated from Neutron Measurements by the HEND Instrument Onboard the 2001 Mars Odyssey Spacecraft, Solar Syst. Res., 38, 253-257, 2004.

Moreno, M. A.: Microorganism transport from Earth to Mars, Nature, 336, 209, 1988.

Murray, J. B., Muller, J.-P., Neukum, G., Werner, S. C., van Gasselt, S., Hauber, E., Markiewicz, W. J., Head, James W., I., Foing, B. H., Page, D., Mitchell, K. L., Portyankina, G., and Co-Investigator Team, T. H.: Evidence from the Mars Express High Resolution Stereo Camera for a frozen sea close to Mars' equator, Nature, 434, 352, 0028-0836, doi:10.1038/nature03379, 2005.

Nelson, G. A.: Fundamental Space Radiobiology, Gravitational and Space Biology Bulletin, 16, 29-36, 2003.

Nugent, J. H.: Molecular-size standards for use in radiationinactivation studies on proteins, Biochem. J., 239, 459-462, 1986.

Orgel, L. E.: Prebiotic Chemistry and the Origin of the RNA World, Critical Reviews in Biochemistry and Molecular Biology, 39, 99-123, 2004.

Pavlov, A. K., Blinov, A. V., and Konstantinov, A. N.: Sterilization of Martian surface by cosmic radiation, Planetary and Space Science, 50, 669-673, 2002.

Schuerger, A. C., Richards, J. T., Newcombe, D. A., and 
Venkateswaran, K.: Rapid inactivation of seven Bacillus spp. under simulated Mars UV irradiation, Icarus, 181, 52-62, doi:10.1016/j.icarus.2005.10.008;, 2006.

Simoneit, B. R. T., Summons, R. E., and Jahnke, L. L.: Biomarkers as Tracers for Life on Early Earth and Mars, Origins of Life and Evolution of Biospheres (Formerly Origins of Life and Evolution of the Biosphere), 28, 475-483, 1998.

Squyres, S. W.: The History of Water on Mars, Ann. Rev. Earth Planet. Sci., 12, 83-106, 1984.

Squyres, S. W., Grotzinger, J. P., Arvidson, R. E., Bell, J. F., I., Calvin, W., Christensen, P. R., Clark, B. C., Crisp, J. A., Farrand, W. H., Herkenhoff, K. E., Johnson, J. R., Klingelhofer, G., Knoll, A. H., McLennan, S. M., McSween, H. Y., J., Morris, R. V., Rice, J. W., J., Rieder, R., and Soderblom, L. A.: In Situ Evidence for an Ancient Aqueous Environment at Meridiani Planum, Mars, Science, 306, 1709-1714, 2004.

Szewzyk, U., Szewzyk, R., and Stenstrom, T.: Thermophilic, Anaerobic Bacteria Isolated from a Deep Borehole in Granite in Sweden, PNAS, 91, 1810-1813, 1994. ten Kate, I. L., Garry, J. R., Peeters, Z., Quinn, R., Foing, B., and Ehrenfreund, P.: Amino acid photostability on the Martian surface, Meteoritics Planetary Sci., 40, 1185-1193, 2005.

Usoskin, I. G., Solanki, S. K., Kovaltsov, G. A., Beer, J., and Kromer, B.: Solar proton events in cosmogenic isotope data, Geophys. Res. Lett., 33, 08 107, doi:10.1029/2006GL026059, 2006.

Vago, J., Gardini, B., Kminek, G., Baglioni, P., Gianfiglio, G., Santovincenzo, A., Bayón, S., and van Winnendael, M.: ExoMars: Searching for Life on the Red Planet, ESA Bulletin, 126, 17-23, 2006.

Wänke, H., Bruckner, J., Dreibus, G., Rieder, R., and Ryabchikov, I.: Chemical Composition of Rocks and Soils at the Pathfinder Site, Space Sci. Rev., 96, 317-330, 2001.

Yen, A. S., Kim, S. S., Hecht, M. H., Frant, M. S., and Murray, B.: Evidence That the Reactivity of the Martian Soil Is Due to Superoxide Ions, Science, 289, 1909-1912, 2000.

Zent, A. P.: On the thickness of the oxidized layer of the Martian regolith, J. Geophys. Res., 103, 31 491-31498, doi:10.1029/98JE01895, 1998. 